\title{
Cause for concern
}

\section{Eric Ashby}

\author{
Victims of Science: The Use of Animals in Research, revised edn \\ By Richard D. Ryder. \\ National Anti-Vivisection Society Ltd, London: 1983. Pp.180. Hbk £6.75, pbk £3.75.
}

NEARLY 20 million motor vehicles are licensed to run on the roads of Britain. Consider what it would be like if this traffic were to be controlled by an Act of Parliament, never amended, dating from the 1870 s, a decade before the internal combustion engine was invented, when there was nothing more dangerous on the roads than horses. A silly speculation? No sillier than the plain fact about the Act of Parliament that controls experiments on animals.

The Act was passed in 1876 , with the prime object of deterring a few scientists from carrying out surgical experiments on conscious animals. Some of those experiments, by all accounts, were horrifying to witness and of dubious scientific value. There were not many of them - a few hundred a year - and, to put the matter in perspective, it has to be remembered that less than ten years before that Act was passed it was still legally permissible in America to own slaves. Today this same Act, unamended, is used to control over 4 million procedures on animals each year. Only a minority of these procedures is surgical; an even smaller minority subjects the animal to pain, for the animals are put under anaesthetic and are killed before they regain consciousness if otherwise they would suffer severe pain.

In a typically British pragmatic way, the Home Office inspectors who supervise the 1876 Act have devised a working relationship with those to whom licences are granted to ensure that animals are treated "with due care and humanity". Though the Act is obsolete its interpretation is not. It covers procedures undreamt of by those who campaigned in the 1870 s for a law to protect animals against abuse from a handful of physiologists and anatomists.

Notwithstanding this liberal and humane interpretation of an obsolete law, the law needs to be changed. It does not, for instance, cover procedures on animals which are not 'experiments', i.e procedures not designed to test a hypothesis, but (for example) to be used for the preparation of a vaccine. Nor does the law control the housing of animals to be used for experiments, nor the sources from which they come. Nor does it take sufficient account of the purpose of an experiment, i.e. whether it is likely to benefit the welfare of human beings or animals. So a campaign to repeal the 1876 Act and to replace it by a law which gives better protection to animals has been under way for some time. It has already 'brought animals into politics': the manifestos of all political parties include a promise to revise the law; the Council of Europe (at a glacial pace) is drawing up a convention to which member states will be asked to subscribe; the British government issued in May 1983 a White Paper (a document of intent) for an updating of the 1876 Act.

Among the campaigners who have succeeded in stirring the conscience of the public over this issue is Richard Ryder. This book is a revised edition of his case studies "of the way man mistreats animals for the purposes of research". It is a catalogue, a very selective one, of the uses to which animals are put in medical and non-medical research. It contains some useful facts and figures, and - its chief virtue - a clear account of the campaign for reform, from the beginning of the 19 th century up to the present. The book is illustrated by lurid coloured plates of animals undergoing experimental surgery, drawn, for some unexplained reason, from Japan, Poland, Mexico, Spain, the Soviet Union, and the USA, not from Britain.

The purpose of Ryder's book is not only to stir the public conscience; it is also (in his own words) "to suggest reforms". It is not Ryder's fault that this is the weakest part of the book, for in the present state of knowledge, the only reform that would satisfy zealots in the animal rights movement would be to discontinue most medical and veterinary research, to abandon the testing of drugs, pesticides, and food-additives before they are put on the market and to

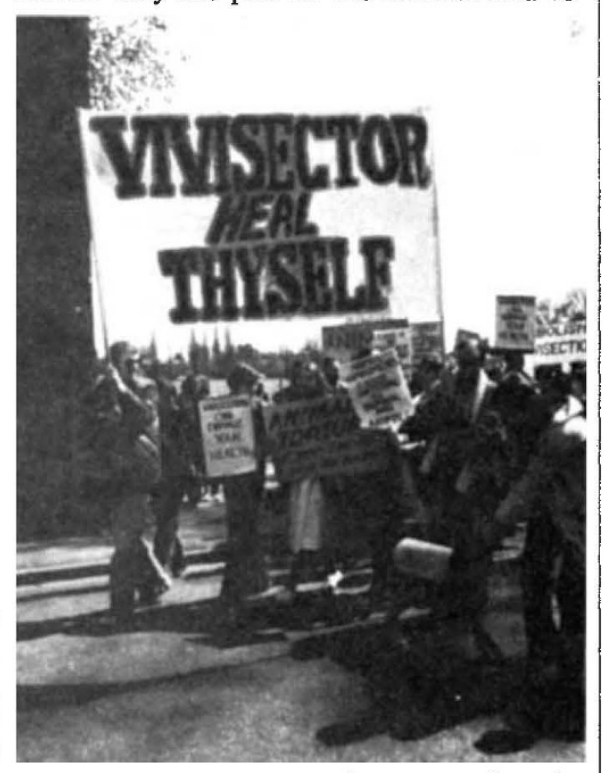

Public concern - a demonstration in Cambridge in 1979. discontinue the raising of cattle, sheep, and poultry (except for their eggs) in favour of vegetarianism. Obviously the zealots are not going to be satisfied. What, then, is the best way, in the interests of animals, to reach an understanding between those who want to protect animals from exploitation on one hand, and on the other hand those who believe that it is essential that, for some purposes, and "with due care and humanity", animals have to be exploited?

Not, in my view, through books like Victims of Science. For one thing, the title is totally misleading. The great majority of animals are not victims of science: they are sacrificed to meet the public demand for safety, not to advance science but to make sure that drugs will not have nasty side effects, that substitutes for sugar will not cause cancer, that mouth washes will not irritate the skin. The animals are victims of the consumer society and it is a pity Ryder - who makes that point clearly in the text - wasn't more precise about the title.

There are other weaknesses about the book. Ryder seems confused about the attitude one should have to medical, as contrasted with non-medical, research. On one page he emphasizes this contrast, as though the use of animals for medical research is, so to speak, a special case. On another page he seems to dismiss the contrast, saying that the only justification for inflicting pain on any animal is that "it must be in terms of benefits accruing to the same individual"'. How much more persuasive he would have been, in the long run, if he had admitted that all of us - animal-protectors and animal-exploiters alike - are up against a daunting ethical problem that has not been solved. Unfortunately Ryder omits from his bibliography, which is disappointingly partisan, some of the thoughtful and sympathetic writing about this dilemma. Why, for instance, is there no reference to Marian Dawkin's book on Animal Suffering? Or (though casually mentioned in the text) to the 340 pages of evidence given to the Select Committee on the Laboratory Animals Protection Bill? Or to the thoughtful essays by Mary Midgley?

Perhaps in the short run sensational advocacy pays off. It could be claimed that the protection of animals, like the protection of the environment, has been promoted by scandalous incidents publicized in the media. But in the long run it is evenhanded honesty that pays. In some of his writing, and in his evidence to committees, Richard Ryder has presented a convincing and well argued case. In this book, however, he is preaching a necessary message - that we should continue to worry about the use of animals for the benefit of human beings - in an unnecessarily shrill voice.

Lord Ashby was chairman of the House of Lords Select Committee appointed to report on the Laboratory Animals Protection Bill in 1979. 